\title{
The Chemical Composition of a Metal/Ceramic Interface on an Atomic Scale: The $\mathrm{Cu} / \mathrm{MgO}\{111\}$ Interface
}

\author{
H. JANG AND D.N. SEIDMAN \\ Northwestern University, Department of Materials Science and Engineering and the Materials Research \\ Center, Robert R. McCormick School of Engineering and Applied Science, Evanston, IL 60208
}

K.L. MERKLE

Angonne National Laboratory, Materials Science Division, Building 212, Argonne, IL 60439

Received September 28, 1992; Revised November 30, 1992.

Keywords: Metal/ceramic interface, internal oxidation, $\mathrm{Cu} / \mathrm{MgO}$ heterophase interface, high resolution electron microscopy, atom-probe field-ion microscopy.

\begin{abstract}
The chemical composition profile across a $\mathrm{Cu} / \mathrm{MgO}\{111\}$-type heterophase interface, produced by the internal oxidation of a $\mathrm{Cu}(\mathrm{Mg})$ single-phase alloy at $1173 \mathrm{~K}$, is measured via atomprobe field-ion microscopy with a spatial resolution of $0.121 \mathrm{~nm}$; this resolution is equal to the interplanar spacing of the $\{222\} \mathrm{MgO}$ planes. In particular, we demonstrate directly that the bonding across a $\mathrm{Cu} / \mathrm{MgO}\{111\}$-type heterophase interface, along a $<111>$ direction common to both the $\mathrm{Cu}$ matrix and an $\mathrm{MgO}$ precipitate, has the sequence $\mathrm{Cu}|\mathrm{O}| \mathrm{Mg} \ldots$ and not $\mathrm{Cu}|\mathrm{Mg}| \mathrm{O} \ldots$... this result is achieved without any deconvolution of the experimental data. Before determining this chemical sequence, it was established, via high-resolution electron microscopy, that the morphology of an $\mathrm{MgO}$ precipitate in a $\mathrm{Cu}$ matrix is an octahedron faceted on $\{111\}$ planes with a cube-on-cube relationship between a precipitate and the matrix; that is, $\{111\}_{\mathrm{Cu}} / /\{222\}_{\mathrm{MgO}}$ and $<110>_{\mathrm{Cu}} / /<110>_{\mathrm{MgO}}$.
\end{abstract}

\section{Introduction}

Metal/ceramic heterophase interfaces are currently receiving a great deal of experimental attention because they are omnipresent in a wide range of materials and structures [1-6]; for example, metal matrix composites with ceramic fibers [7], metal/ceramic nanocomposites [8], machinable ceramics, metallization of microelectronics circuit structures [9], semiconductor devices, oxide scales on metals [10], and dispersion-hardened alloys [11]. The cohesive energies of metal/ceramic interfaces have also been the focus of much theoretical effort, as ultimately the behavior of a metal/ceramic heterophase interface in service is determined by how well these rather disparate materials adhere to one another [12-14]. In particular, on the experimental side, a great deal of energy has been expended employing high-resolution electron microscopy (HREM) to determine the terminating plane on the oxide side of metal/metal oxide heterophase interfaces by comparing HREM micrographs with micrographs computed using imagesimulation techniques [15-17].

In this paper we present the results of a different approach for studying the chemical character of metal/ceramic heterophase interfaces. We employ atom-probe field-ion microscopy (APFIM) to ascertain directly-on an atomic scale - the chemical compositions of individual atomic planes in traversing $\mathrm{Cu} / \mathrm{MgO}\{111\}$-type 
interfaces that are produced by internally oxidizing [18-25] a $\mathrm{Cu}(\mathrm{Mg})$ single-phase alloy. This is a particularly interesting metal/ceramic interface, as it involves the bonding of a noble freeelectron metal $(\mathrm{Cu})$ to a strongly heteropolar metal oxide (MgO). The calculated lattice misfit parameter $(\eta)$ is 0.1483 for the $\mathrm{Cu} / \mathrm{MgO}$ system. The heterophase interfaces formed by internal oxidation of a $\mathrm{Cu}(\mathrm{Mg})$ alloy have the following important advantages: 1) Impurity atom segregation is essentially nil-our atom probe observations substantiate this point-because of the large total interfacial area per unit volume; 2 ) common low-index directions between the $\mathrm{MgO}$ precipitates and the matrix are present that have interplanar spacings suitable for HREM; and 3) all the $\mathrm{MgO}$ precipitates that form have a simple octahedral shape bounded by the low-index $\{222\}$ planes. The APFIM technique is used to both supplement and complement transmission electron microscopy (TEM) and HREM observations of the same interface. Using APFIM, we demonstrate in a direct manner-without data deconvolution - that the bonding across a $\mathrm{Cu} / \mathrm{MgO}\{111\}$-type interface, along a common $<111>$ direction, has the bonding sequence $\mathrm{Cu}|\mathrm{O}| \mathrm{Mg} .$. and not $\mathrm{Cu}|\mathrm{Mg}| \mathrm{O} \ldots$; the spacing between the $\{222\}$ planes of $\mathrm{MgO}$ is 0.121 $\mathrm{nm}$, and this is the APFIM spatial resolution of a composition profile along a $<111>$ direction.

\section{Experimental Procedures}

Three different $\mathrm{Cu}(\mathrm{Mg})$ alloys were prepared by melting ASARCO copper (99.998+ at.\% pure) and Johnson Matthey magnesium (99.98 at.\% pure) in a high-purity graphite crucible covered with a loose-fitting graphite cap; the copper was placed on top of the magnesium in the graphite crucible to confine the magnesium vapor during melting of the two elements. Prior to using the high-purity graphite crucible, it was heated for 4 hours at $1473 \mathrm{~K}$ under high-vacuum conditions. The covered graphite crucible, containing the copper and magnesium charge, was placed in a quartz tube and evacuated to $1.3 \cdot 10^{-2} \mathrm{~Pa}$, and the quartz tube was backfilled with agron gas and sealed. The small cylindrically shaped
$\mathrm{Cu}(\mathrm{Mg})$ ingots produced in this manner each weighed approximately $26 \mathrm{~g}$. The particular alloy compositions prepared were $\mathrm{Cu}-0.16$ at.\% $\mathrm{Mg}$, $\mathrm{Cu}-0.7$ at. $\% \mathrm{Mg}$ and $\mathrm{Cu}-2.8$ at. $\% \mathrm{Mg}$; these $\mathrm{Mg}$ concentrations correspond to single-phase solidsolution alloys at $1173 \mathrm{~K}$ [26]. The ingots were rolled into $125-\mu \mathrm{m}$ thick sheets for transmission electron microscopy (TEM) and HREM studies, or drawn into $152-\mu \mathrm{m}$ diameter wires for APFIM studies.

$\mathrm{Cu} / \mathrm{MgO}$ internal interfaces were formed by internally oxidizing those alloy specimens utilizing the Rhines pack method [20,21]; this pack consists of a powder mixture of $\mathrm{Cu}$ plus $\mathrm{Cu}_{2} \mathrm{O}$ plus $\mathrm{Al}_{2} \mathrm{O}_{3}$ (1:1:1 by volume), which is heated in a partial pressure of oxygen equal to the decomposition pressure of cuprous oxide, approximately $\mathrm{P}_{\mathrm{O}_{2}}<10^{-2} \mathrm{~Pa}$ [21]. Figure 1 exhibits the rootmean squared-diffusion distance $\left(\sqrt{ }<\mathrm{X}^{2}>\right)$ of the oxygen diffusion front (in $\mathrm{cm}$ ) versus time (in min.) for several internal oxidation temperatures and two different $\mathrm{Mg}$ concentrations -0.7 and 2.8 at. $\% \mathrm{Mg}$-for a plate geometry. This plot was created from the experimental data presented in [21]. Figure 1 demonstrates that the time required for complete internal oxidation increases as the $\mathrm{Mg}$ concentration increases from 0.7 to 2.8 at.\% $\mathrm{Mg}$. This data also demonstrates that the time for the complete internal oxidation is about $1800 \mathrm{~s}$ for the foil thickness we employ, at $1173 \mathrm{~K}$, for the $2.8 \mathrm{at} \% \mathrm{Mg}$ alloy. The time required to internally oxidize a cylinder completely is approximately $50 \%$ of the time to achieve the same condition for a plate [27]. Therefore, an $1800 \mathrm{~s}$ treatment results in the complete internal oxidation of the $152-\mu \mathrm{m}$ diameter wires with 2.8 at.\% $\mathrm{Mg}$. To realize a high probability of finding an MgO precipitate in an APFIM specimen, experiments were performed to determine the optimum $\mathrm{Mg}$ concentration, internal oxidation temperature, and time for achieving a high number density $\left(>5 \cdot 10^{21} \mathrm{~m}^{-3}\right)$ of small-diameter precipitates $(<20 \mathrm{~nm})$. There are several parameters that control the number density and the size of the precipitate in the process of internal oxidation. They are the composition of an alloy, the oxidation temperature, and oxidation time. From kinetic studies of internal oxidation, it is known that the mobility of oxygen, and the difference in the chemical affinity 


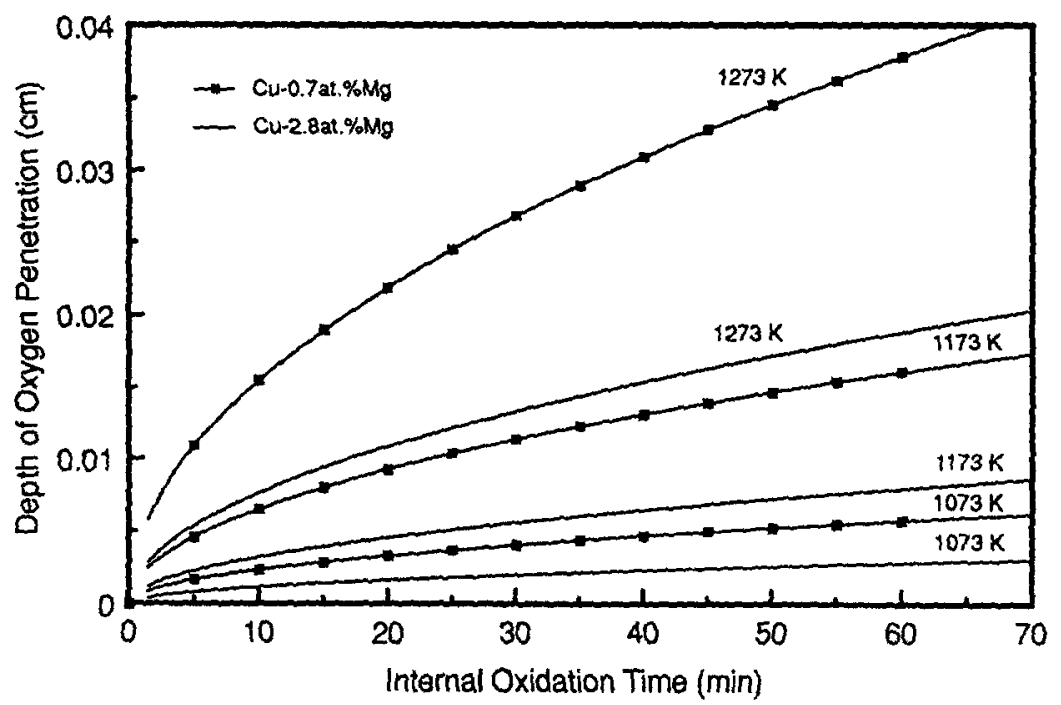

Fig. 1. A plot of the root mean-squared diffusion distance $\left(\sqrt{ }<X^{2}>\right)$ in $\mathrm{cm}$ for the oxygen diffusion front versus time (min.) in $\mathrm{Cu}(\mathrm{Mg})$ alloys for two different $\mathrm{Cu}(\mathrm{Mg})$ alloys -0.7 and 2.8 at.\% $\mathrm{Mg}$. The curves were calculated employing data given in [21].

of oxygen for an alloying element and a matrix element are the main controlling factors in determining the number density and diameter of metal oxide precipitates. A series of experiments were carried out to obtain a suitable precipitate diameter and number density by varying those parameters. The optimum conditions for combined TEM/APFIM experiments were found to be a $\mathrm{Cu}-2.8$ at. \% $\mathrm{Mg}$ alloy, an internal oxidation temperature of $1173 \mathrm{~K}$, and an oxidizing time of $1800 \mathrm{~s}$ for both the thin sheets and wires.

For the TEM and HREM studies 3-mm diameter disks were punched out of the thin sheets, and a twin-jet polisher (Tenupol) employing a 30 vol.\% nitric acid $/ 70$ vol.\% methanol solution at $243 \mathrm{~K}$ was used to prepare electron transparent thin regions. The APFIM specimens were electropolished to a sharply pointed tip with a radius of curvature ranging from $20 \mathrm{~nm}$ to $80 \mathrm{~nm}$, after the internal oxidation procedure, utilizing an electrolytic solution with the composition $100 \mathrm{~g}$ $\mathrm{Na}_{2} \mathrm{CrO}_{4}: 4 \mathrm{H}_{2} \mathrm{O}$ in $900 \mathrm{ml}$ of acetic acid. A stainless steel cathode in the form of a $25-\mathrm{mm}$ diameter circular loop was used to electropolish the wire-shaped specimens, and the electrolyte was placed in the loop to form a meniscus [28]. To examine the wire-shaped specimens by TEM, a specially fabricated double-tilt stage was em- ployed for an Hitachi $700 \mathrm{H} 200 \mathrm{kV}$ electron microscope [28]. This double-tilt stage is unique, as it allows us to examine the same wire FIM specimen both prior to and after an atom-probe study, as well as at any stage of the electropolishing procedure [28].

\section{Transmission Electron Microscope Results}

First, conventional TEM is used to determine both the number density and size distribution of $\mathrm{MgO}$ precipitates in order to be certain that a precipitate is found in the small volumeapproximately $10^{-21} \mathrm{~m}^{3}$ - of an FIM tip, during the course of a pulsed-field evaporation dissection of a tip of an FIM specimen on an atomby-atom basis. Figure $2(a)$ is a dark-field TEM micrograph of $\mathrm{MgO}$ precipitates in an internally oxidized $\mathrm{Cu}-2.8$ at.\% $\mathrm{Mg}$ alloy. Note the typical "coffee-bean" strain-field contrast effects, and the line of no-contrast perpendicular to the operating reflection $\mathbf{g}_{020}$ [29]. The contrast variations from precipitate to precipitate are due to the depth oscillations with the position of a precipitate in a thin foil [30]. Figure $2(b)$ is a bright-field micrograph in a multibeam [100] zone-axis condition. A precipitate imaged under 

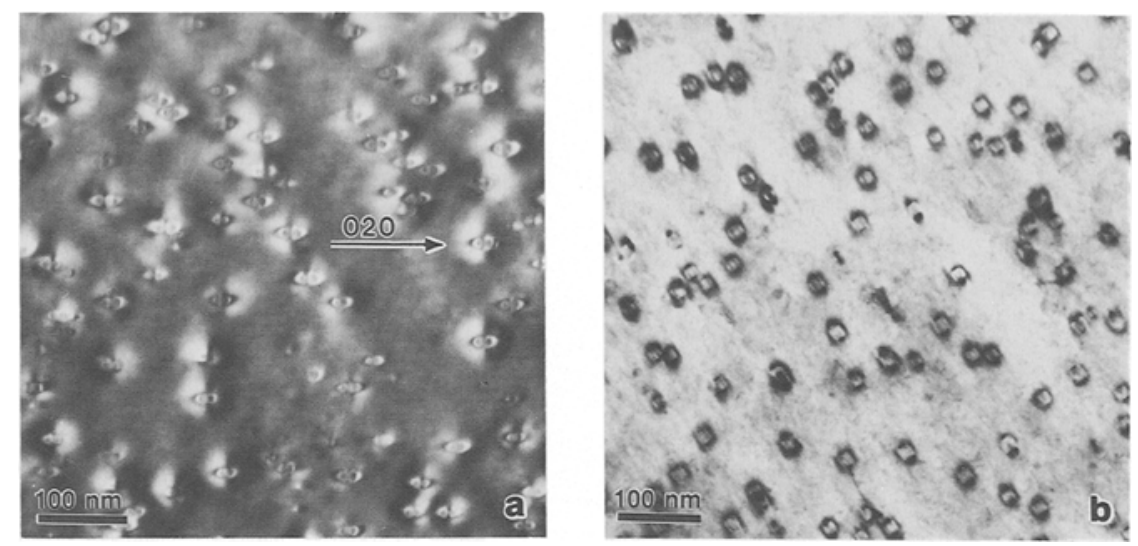

Fig. 2. (a) A dark-field transmission electron micrograph of $\mathrm{MgO}$ precipitates in a $\mathrm{Cu}$ matrix produced by internal oxidation of a $\mathrm{Cu}-2.8$ at.\% $\mathrm{Mg}$ alloy. The operating reflection is $020(\mathrm{~g} 020)$, and the precipitates exhibit classical "coffee-bean" strain-field contrast. The line of no contrast is perpendicular to $\mathrm{g}_{020}$. (b) A bright-field transmission electron micrograph of $\mathrm{MgO}$ precipitates in a $\mathrm{Cu}$ matrix along a [100] zone axis with a number of reflections excited-this is a so-called multibeam micrograph.

multibeam conditions reveals the shape of a precipitate without severe strain-field contrast and allows a rough estimate of the precipitate size [31]. The actual diameter of an MgO precipitate is difficult to estimate precisely from the micrographs exhibited in figure 2 , since the observed shape and amount of strain-field contrast depend strongly on the diffraction conditions [29].

The moiré fringe method is a more reliable measure of the exact dimensions of a precipitate [32]. Figure 3 displays a TEM micrograph of faceted $\mathrm{MgO}$ precipitates, viewed along a [123] direction, that exhibit parallel (11̄i) moiré fringes. The moiré fringe spacing is $1.5 \mathrm{~nm}$, and the average diameter of the precipitates studied by this technique is $16.2 \mathrm{~nm}$, with a quite broad size distribution [33].

To determine the number density of $\mathrm{MgO}$ precipitates, a wire specimen is used, since this simplifies the calculation of the volume corresponding to the area observed. From TEM micrographs of a wire specimen (shown in figure 10 in detail), we determined that the number density of precipitates is approximately $5 \cdot 10^{21} \mathrm{~m}^{-3}$; this number density is high enough for the precipitates to be readily detected in the tip of an FIM specimen.

\section{High-Resolution Electron Microscope Results}

To investigate the atomic scale structure of a $\mathrm{Cu} / \mathrm{MgO}\{111\}$-type heterophase interface, and to ascertain its geometric shape, HREM observations were performed on $\mathrm{Cu}-2.8$ at. $\% \mathrm{Mg}$ specimens that had been internally oxidized, as described in section 2 . The lattice misfit parameter $(\eta)$ is given by $\eta=2\left[\left(a_{\mathrm{MgO}}-a_{\mathrm{Cu}}\right) /\left(a_{\mathrm{MgO}}+a_{\mathrm{Cu}}\right)\right]$, where the $a$ 's are the lattice parameters of the two phases; its calculated value is 0.1483 for $a_{\mathrm{Cu}}=0.362 \mathrm{~nm}$, and $a_{\mathrm{MgO}}=0.42 \mathrm{~nm}$. Axial illumination in an Hitachi H9000 HREM allows the direct observation of the configuration of atoms near an internal interface when proper operating conditions are met [34]. The highresolution micrographs now discussed demonstrate that the $\mathrm{MgO}$ precipitates have an octahedral shape, with a cube-on-cube relation on the $\{111\}$ planes. First, figure 4 exhibits an HREM image (defocus value is $69.4 \mathrm{~nm}$ at 300 $\mathrm{kV}$ ) of an $\mathrm{MgO}$ precipitate in a $\mathrm{Cu}$ matrix with a common [100] zone axis for both the $\mathrm{MgO}$ precipitate and the $\mathrm{Cu}$ matrix. The $0.21 \mathrm{~nm}$ interplanar spacing of the (200) planes of this $\mathrm{MgO}$ precipitate, and the $0.181 \mathrm{~nm}$ interplanar spacing of the (200) planes of the copper matrix are indicated. Note that the projection of this precipitate on the (100) plane is an approxi- 


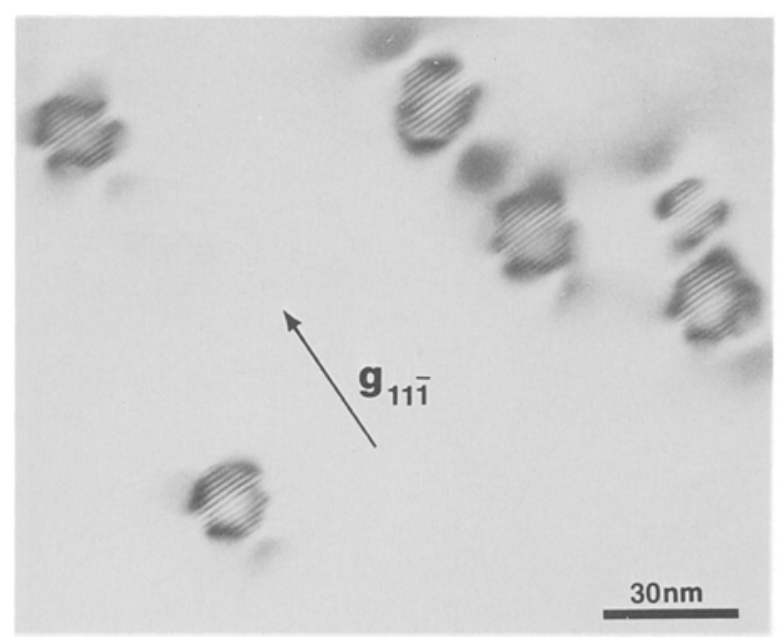

Fig. 3. A (11) moiré fringe pattern of a faceted $\mathrm{MgO}$ precipitate with the image plane close to (123). The operating reflection for this micrograph is $11 \overline{1}\left(g_{11 \overline{1}}\right)$. The shape of the fringes represents the shape of the precipitate viewed along a [123] direction. The strain-field contrast pattern near the $\mathrm{MgO}$ precipitates displays a different shape compared to the pattern seen in Fig. 2; this demonstrates that the contrast changes according to the orientation of the specimen relative to the electron beam.

mately square-shaped figure; two of the sides are, however, slightly curved - the rounding effect at the corners is probably due to the anisotropy of the interfacial free energy on a Wulff plot [35]. The truncation of an octahedron by the $\{100\}$-type planes gives rise to squares of different dimensions; this is the truncation due to the intersection with the surfaces of the specimen. Second, figure 5 is a HREM image (defocus value of $65.1 \mathrm{~nm}$ at $300 \mathrm{kV}$ ) recorded employing a common [110] zone axis for an $\mathrm{MgO}$ precipitate in a $\mathrm{Cu}$ matrix. This micrograph shows quite clearly that the projection of this precipitate on a (110) plane has an hexagonal-shape, although it is not a perfect hexagon because of moiré thickness effects resulting from the inclined $\{111\}$ planes; the hexagonal shape arises from the truncation of an octahedron by $\{110\}$ type surfaces, when they do not pass through its apex. The $0.242 \mathrm{~nm}$ interplanar spacing of the (111) planes of this $\mathrm{MgO}$ precipitate, and the $0.209 \mathrm{~nm}$ interplanar spacing of the (111) planes of the copper matrix are indicated. The diameter of this $\mathrm{MgO}$ precipitate is $10 \mathrm{~nm}$. Third, figure 6 is an HREM image (defocus value of 44

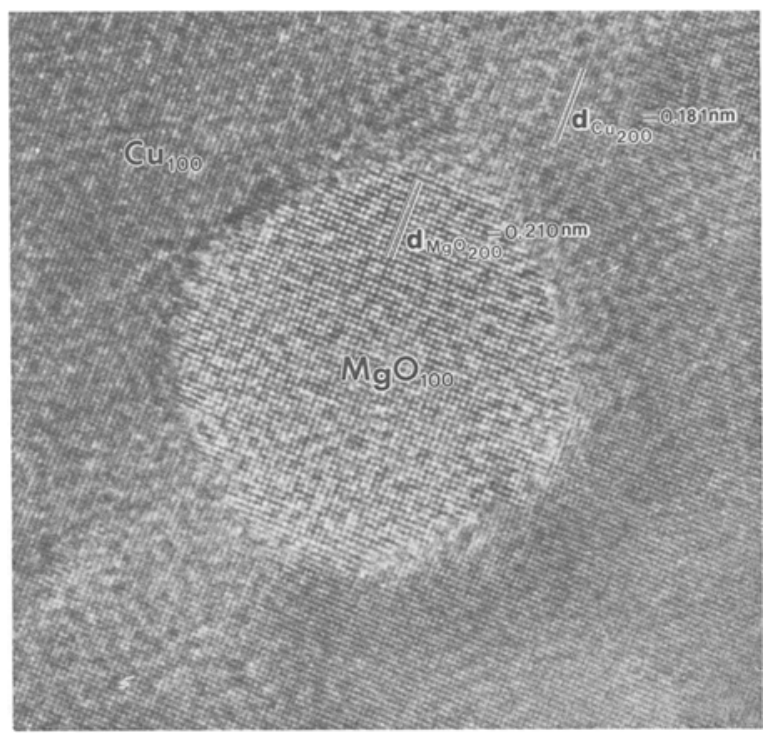

Fig. 4. A high-resolution electron microscope image of an $\mathrm{MgO}$ precipitate in the $\mathrm{Cu}$ matrix viewed along a [100] zone axis; the defocus value is $69.4 \mathrm{~nm}$ at an operating voltage of $300 \mathrm{kV}$. The $0.21 \mathrm{~nm}$ interplanar spacing of the (200) planes in the $\mathrm{MgO}$ precipitate is indicated on the precipitate, and the $0.181 \mathrm{~nm}$ interplanar spacings of the (200) planes in the Cu matrix is indicated on it. The atomic columns in both the precipitate and the matrix exhibit the same crystallographic orientation relationship - the cube-on-cube orientation.

$\mathrm{nm}$ ), also recorded employing a common [110] zone axis, and exhibiting a diamond-shaped $\mathrm{MgO}$ projection on the (110) plane; this shape is a result of the truncation of an octahedron by a $\{110\}$-type surface passing through its apex. To illustrate these observations, figure 7 displays the octahedral shape of an $\mathrm{MgO}$ precipitate, as deduced from the HREM images, with the major crystallographic planes indicated. This figure also includes the possible two-dimensional projections of an octahedron created by $\{001\}$ or $\{110\}$ surface truncations. The $\{111\}$-type faceted planes seen in figures 4 to 7 can be made even flatter by a post-internal-oxidation annealing treatment under high-vacuum conditions $[34,36]$. The number density, however, is lower, and the precipitate diameter greater30 to $300 \mathrm{~nm}$ - when this post-internal-oxidation treatment is employed; therefore, we restricted the present experiments to short internal oxidation times; no post-vacuum annealing treatments were employed. Those HREM images 


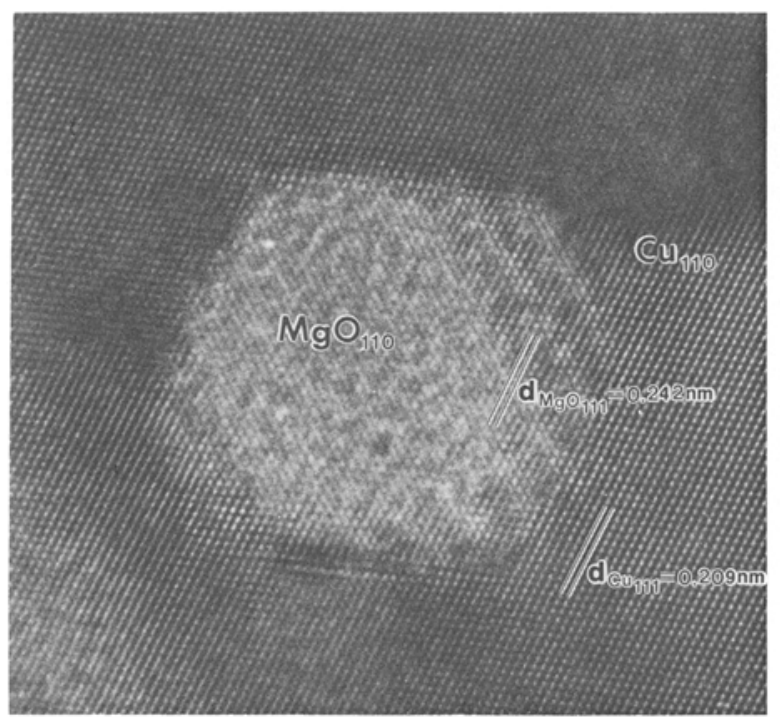

Fig. 5. A high-resolution electron microscope image of an $\mathrm{MgO}$ precipitate in the $\mathrm{Cu}$ matrix viewed along a common [110] zone axis; the defocus value is $65.1 \mathrm{~nm}$, and the operating voltage is $300 \mathrm{kV}$. The $\mathrm{MgO}$ precipitate is faceted on $\{222\}$-type planes, and the truncation of the $\mathrm{MgO}$ precipitate by (110) surfaces of the specimen results in an hexagonal-shaped image. This is additional evidence for a cube-on-cube orientation relation between the two phases. The $0.242 \mathrm{~nm}$ interplanar spacing of the (111) planes in the $\mathrm{MgO}$ precipitate is indicated on the precipitate, and the $0.209 \mathrm{~nm}$ interplanar spacings of the (111) planes in the $\mathrm{Cu}$ matrix is indicated on it.

also demonstrate that the orientation relationship is cube-on-cube ${ }^{1}$ with the $\mathrm{Cu}$ matrix, as found in previous investigations $[17,34,36]$, with an octahedral-shaped precipitate that is faceted on $\{111\}$ planes.

Figure 8 is an HREM micrograph recorded employing a common [110] zone axis (defocus value of $65.1 \mathrm{~nm}$ at $300 \mathrm{kV}$ ) that exhibits misfit dislocations at the interface between an $\mathrm{MgO}$ precipitate and the $\mathrm{Cu}$ matrix. The average spacing between the observed misfit dislocations is approximately $1.32 \mathrm{~nm}$, as estimated from figure 8. Thus the lattice misfit between the $\mathrm{MgO}$ precipitate and the $\mathrm{Cu}$ matrix appears to be accommodated almost completely by localized misfit dislocations; although some residual elastic straining may also be present at $\mathrm{Cu} / \mathrm{MgO}$ $\{111\}$-type interfaces. It is interesting to note that in spite of the large value of $\eta(14.83 \%)$ the

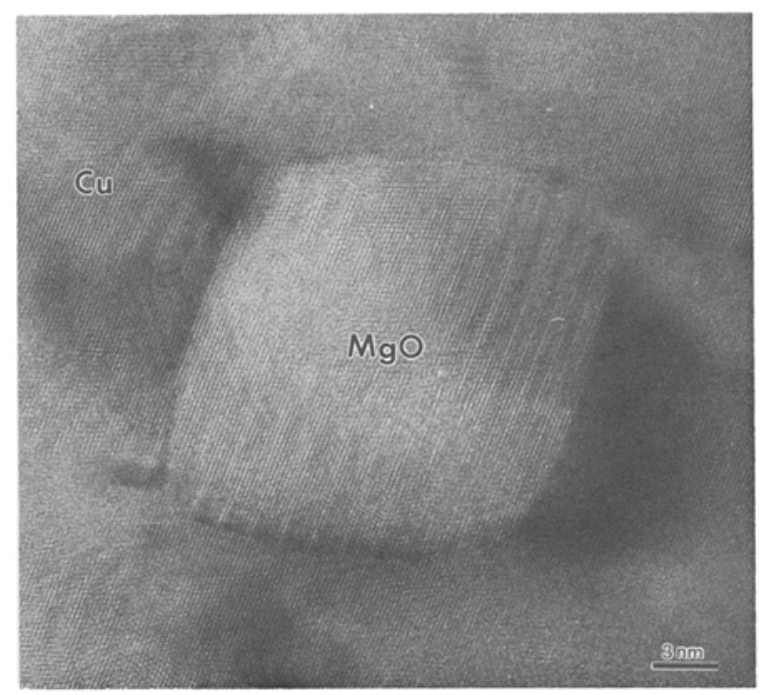

Fig. 6. A high-resolution electron microscope of an $\mathrm{MgO}$ precipitate in the $\mathrm{Cu}$ matrix viewed along a common [110] zone axis; defocus value is $44 \mathrm{~nm}$, and the operating voltage is $300 \mathrm{kV}$. The truncation of an $\mathrm{MgO}$ precipitate by (110) surfaces of the specimen results in a diamond-shaped image, as is expected when (110) planes pass through the apex of an octahedron.

precipitate is semi-coherent with the matrix [34, $36]$. Since the interface contains a $2-[\mathrm{D}]$ hexagonal network of misfit dislocations that would, in general, be inclined to the viewing direction, a detailed contrast analysis would be necessary to determine the degree of misfit localization. The spacing between misfit dislocations $\left(S_{D}\right)$ is given by $|\overline{\mathbf{b}}| / \alpha$, where $\overline{\mathbf{b}}$ is the Burgers vector of the edge dislocations in $\mathrm{Cu}(0.256 \mathrm{~nm})$, and $\alpha$ is the fractional lattice parameter mismatch with respect to $\mathrm{Cu}(0.16)$. Thus, the value of $S_{D}$ in the $\{111\}$-type plane is $1.6 \mathrm{~nm}$ along a $<110>$ type direction. The projection of this $S_{D}$ onto the $\{110\}$-type plane, along <112>-type direction, is given by $\sqrt{3} / 2$ and is equal to $1.38 \mathrm{~nm}^{2}$ Therefore, the fractional difference between the calculated misfit dislocation spacing $(1.38 \mathrm{~nm})$ and the observed spacing $(\approx 1.32 \mathrm{~nm})$ is small.

Figure 9 demonstrates the atomic mismatch across a $\mathrm{Cu} / \mathrm{MgO}\{111\}$ heterophase interface using a hard-sphere model. Misfit dislocations appear in this hard-sphere model at approximately the correct spacing, without employing atomic relaxations, as expected, since six interatomic distances in $\mathrm{MgO}$ correspond (within 

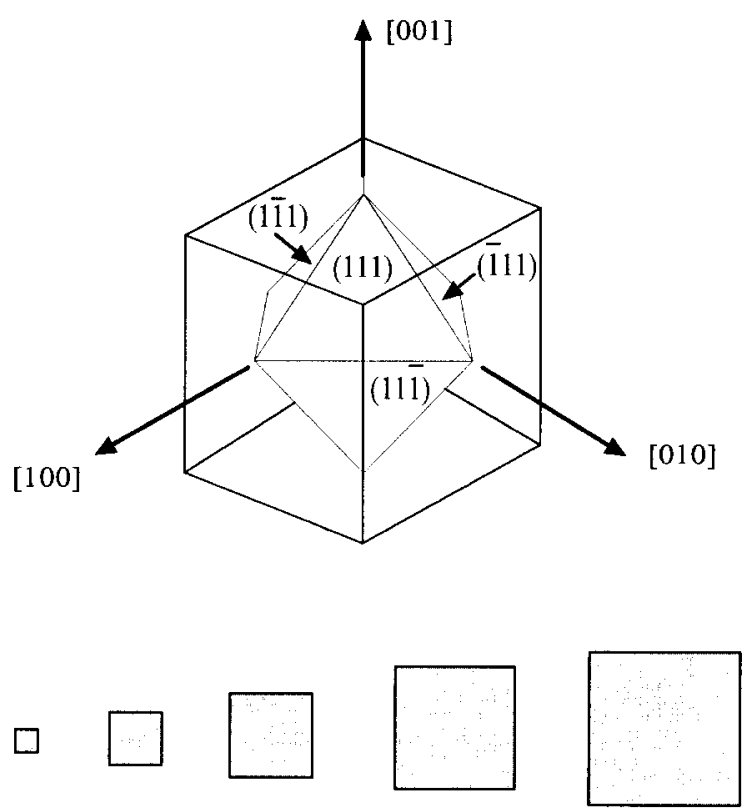

(a) Truncated by $\{001\}$ planes
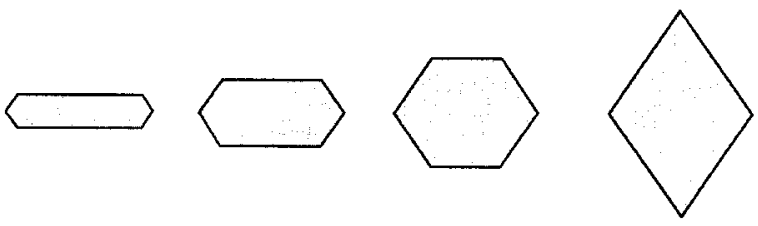

(b) Truncated by $\{110\}$ planes

Fig. 7. A schematic drawing of an $\mathrm{MgO}$ precipitate with the major crystallographic directions indicated. The precipitate has an octahedral shape, and is faceted on $\{111\}$ planes. The relationship between the $\mathrm{MgO}$ precipitate and the $\mathrm{Cu}$ matrix is cube-on-cube. It also shows possible two-dimensional projections of an octahedrally shaped $\mathrm{MgO}$ precipitate by a series of truncations: (a) truncated by $\{001\}$ specimen surfaces; $(b)$ truncated by $\{110\}$ specimen surfaces.

$0.56 \%)$ to seven interatomic distances in copper. This is clearly seen in figure 9 , which is a side view of the $\mathrm{Cu} / \mathrm{MgO}\{111\}$ heterophase interface along a $<110>$ direction.

\section{Atom-Probe Field-Ion Microscope Results}

For a chemical analysis of a $\mathrm{Cu} / \mathrm{MgO}\{111\}$-type interface, a sharply pointed atom-probe spec-

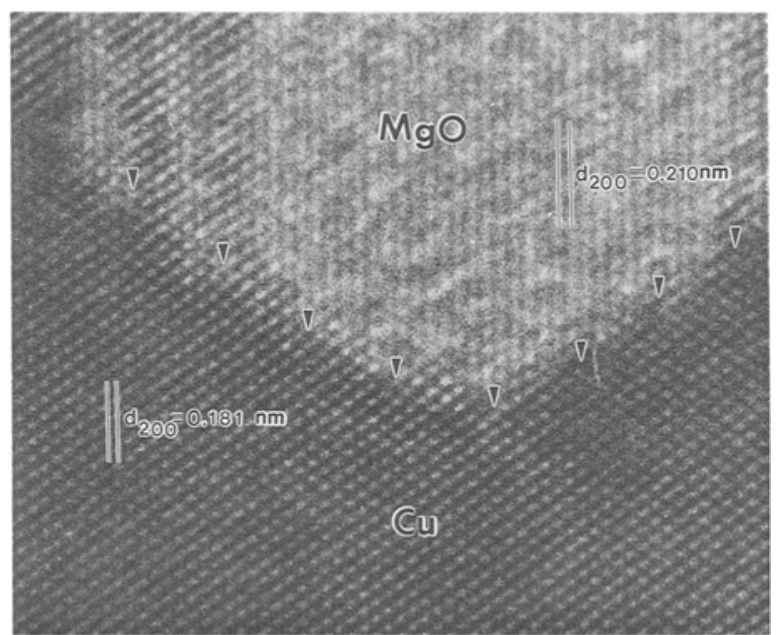

Fig. 8. A high-resolution electron microscope image exhibiting a semicoherent interface between an $\mathrm{MgO}$ precipitate and the $\mathrm{Cu}$ matrix. The presence of misfit dislocations at an interface is indicated by black arrows. The average distance between misfit dislocations is estimated to be approximately $1.32 \mathrm{~nm}$ from this micrograph. The image was recorded with a common [110] zone axis at a defocus value of 65.1 $\mathrm{nm}$, and an operating voltage of $300 \mathrm{kV}$.

imen with a tip radius of approximately 65.8 $\mathrm{nm}$, in the region of the (111) pole, is employed. Figure 10 is a TEM micrograph of an FIM specimen containing $\mathrm{MgO}$ precipitates. From this TEM micrograph, it is seen that the FIM specimen contains uniformly aligned $\mathrm{MgO}$ precipitates exhibiting a directional consistency with respect to the fiber axis of the wire. This axis is a [111] direction, as determined from careful TEM tilting experiments. Hence, this observation is consistent with the known experimental results on wire textures of recrystallized $\mathrm{Cu}$ [37]; it is noted, however, that recrystallized $\mathrm{Cu}$ can exhibit several different textures - [100], [111], [112]-depending on the amount of plastic reduction, the alloying element, and annealing temperature [37]. Note that the number density of $\mathrm{MgO}$ precipitates is high enough that the pulsed field-evaporation of this specimen is likely to result in the random intersection of the surface of the FIM tip with a precipitate. This is a crucial point, since if the number density of precipitates is not high enough then the probability of finding an $\mathrm{MgO}$ precipitate in the volume of 


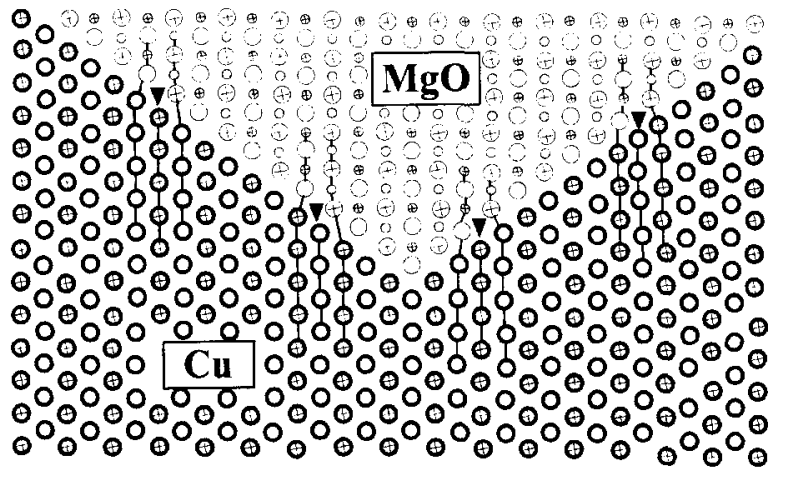

:OXYGEN ION O:Mg ION O: CU ATOM

Fig. 9. Hard-sphere model of a heterophase interface between $\mathrm{Cu}$ and $\mathrm{MgO}$. An open circle represents an atom in the first $\{110\}$ and a circle with an $X$ sign in its centre represents an atom in the second $\{110\}$ plane (side view). The black arrows indicate the presence of the geometrically necessary misfit dislocations.

an FIM tip is essentially nil. Alternatively, it is possible to use a combination of TEM and careful electrochemical backpolishing techniques to place a preselected metal oxide precipitate in the field-of-view of a field-ion microscope image [28, 38].

Figure 11 is a schematic drawing illustrating the relationship between an $\mathrm{MgO}$ precipitate and the chevron ion detector in the atom probe [39a]. The MgO precipitate sits in an FIM specimen such that a $\{222\}$-type plane is parallel to the channel electron multiplier array containing a circular probe hole; that is, for instance, a (222) bounding plane of an octahedral-shaped $\mathrm{MgO}$ precipitate is parallel to a (111) plane of the $\mathrm{Cu}$ matrix. The distance from the probe hole to the FIM is typically between 4 and $6 \mathrm{~cm}$, and the distance from the FIM tip to the chevron ion detector is approximately $2.24 \mathrm{~m}$; the chevron ion detector consists of two channel electron multiplier arrays in series to yield a gain of $\approx 10^{6}$ for a single ion [39b]. The projected diameter of the probe hole on the surface of the FIM tip is varied by changing the distance between the FIM specimen and the channel electron multiplier array [39a]. In the cases to be discussed (see figures 12 to 16 ), this distance was adjusted such that the projected diameter of the probe hole is less than the diameter of a precipitate. A pulsed

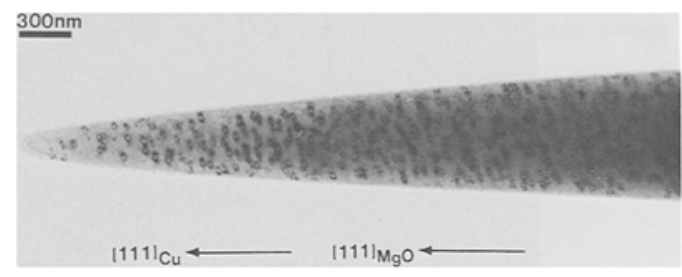

Fig. 10. A transmission electron micrograph of a $\mathrm{Cu}$ field-ion microscope specimen containing a high number density of $\mathrm{MgO}$ precipitates. The $\mathrm{MgO}$ precipitates are all aligned in the same direction with respect to the matrix - that is, along a <111>-type direction; thus, a $\{111\}$-type plane of a $\mathrm{MgO}$ precipitate is parallel to a corresponding $\{111\}$-type plane of the Cu matrix.

dissection process consists of applying a series of pulse voltages $\left(V_{p}\right)$ on top of a steady-state imaging voltage $\left(V_{d c}\right)$, as this results in the dissection of a specimen on an atom-by-atom basis; pulsed field-evaporation is a highly controllable process that has been successfully employed to observe individual point defects - vacancies and self-interstitial atoms - in the bulk of specimens [40], as well as small precipitates in metal alloys [41-45]. As illustrated in figure 11, all the atoms in the cylinder of material with the diameter $D$ are analyzed - that is, their mass-to-charge state ratios are determined - on an atom-by-atom basis. For the geometry illustrated in figure 11 , no matrix correction to the composition of a precipitate is required; alternatively, if the diameter of a precipitate is smaller than the projected diameter of the probe hole on a precipitate, then there is a potential correction to a precipitate's composition. In the case of $\mathrm{MgO}$ precipitates, there is no solid solubility of $\mathrm{Cu}$ in $\mathrm{MgO}$; hence, even if $\mathrm{Cu}$ is detected while dissecting a precipitate, this is $\mathrm{Cu}$ from the matrix and not from the precipitate; the problem of a possible matrix contribution to a precipitate has been dealt with in some detail elsewhere [46].

The same specimen exhibited in figure 10 was transferred to our atom probe for a chemical analysis of a $\{111\}$-type interface. Figure 12 is an FIM micrograph exhibiting an MgO precipitate in the $\mathrm{Cu}$ matrix. The heterophase interface of the $\mathrm{MgO}$ precipitate is parallel to the (111) planes of the $\mathrm{Cu}$ matrix; this is consistent with the HREM observations, and it also implies that 


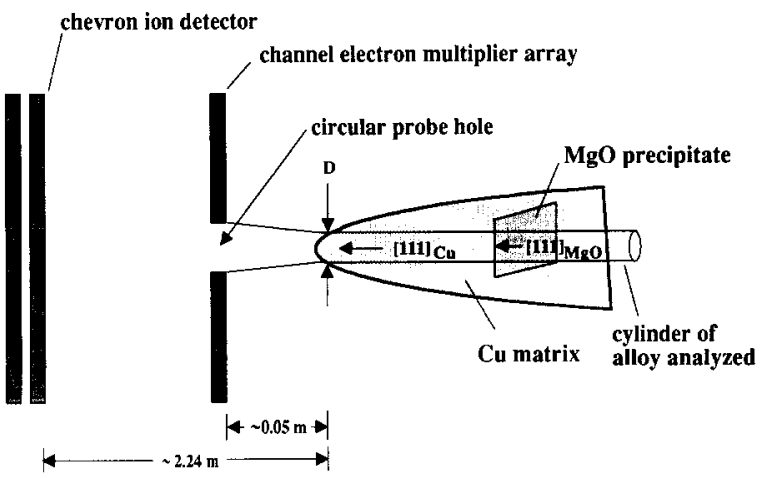

Fig. 11. The geometry employed for analyzing a $\mathrm{Cu} / \mathrm{MgO}$ interface, with the plane of the channel electron multiplier array containing the probe hole parallel to a $\{222\}$ plane of the $\mathrm{MgO}$ precipitate. The projected diameter of the circular probe hole on the surface of the field-ion microscope tip is indicated by the letter $\mathrm{D}$. The pulsed field-evaporated ions pass through the probe hole in the channel electron multiplier array on their journey to the chevron ion detector; the latter consists of two channel electron multiplier arrays in series with an overall gain of $10^{6}$ for an individual ion. The distance from the field-ion microscope tip to the channel multiplier array is typically between $4 \mathrm{~cm}$ and $6 \mathrm{~cm}$, while the distance to the chevron ion detector is $\approx$ $2.24 \mathrm{~m}$. The APFIM spatial resolution of a composition profile across a $\mathrm{Cu} / \mathrm{MgO}\{111\}$ interface-along a common $<111>$ direction - is determined by the interplanar spacing of the $\{222\}$ planes of an $\mathrm{MgO}$ precipitate $-0.121 \mathrm{~nm}$. This schematic diagram is not to scale.

the exposed plane of the precipitate is a $(222)_{\mathrm{MgO}}$ plane. The approximate diameter of this precipitate is $7.3 \mathrm{~nm} .{ }^{3}$ Note the projection of the probe hole onto the FIM image at approximately 10 o'clock near the 111 pole. Figure 13 is a series of FIM micrographs recorded at various stages of a pulsed field-evaporation dissection sequence of this $\mathrm{MgO}$ precipitate; the actual dissection process is on an atom-by-atom basis, and these six FIM images are simply representative of this process. Image 1 is at the beginning of the pulsed-field dissection process of this precipitate, and by image 6 the $\mathrm{MgO}$ precipitate has been completely removed; the black arrow heads point at the $\mathrm{MgO}$ precipitate. It is emphasized that both the $\mathrm{MgO}$ precipitate and the $\mathrm{Cu}$ matrix are simultaneously removed by this technique see figure 11. Also note that individual atoms within the $\mathrm{MgO}$ precipitate are resolved at different stages of its dissection; furthermore, the

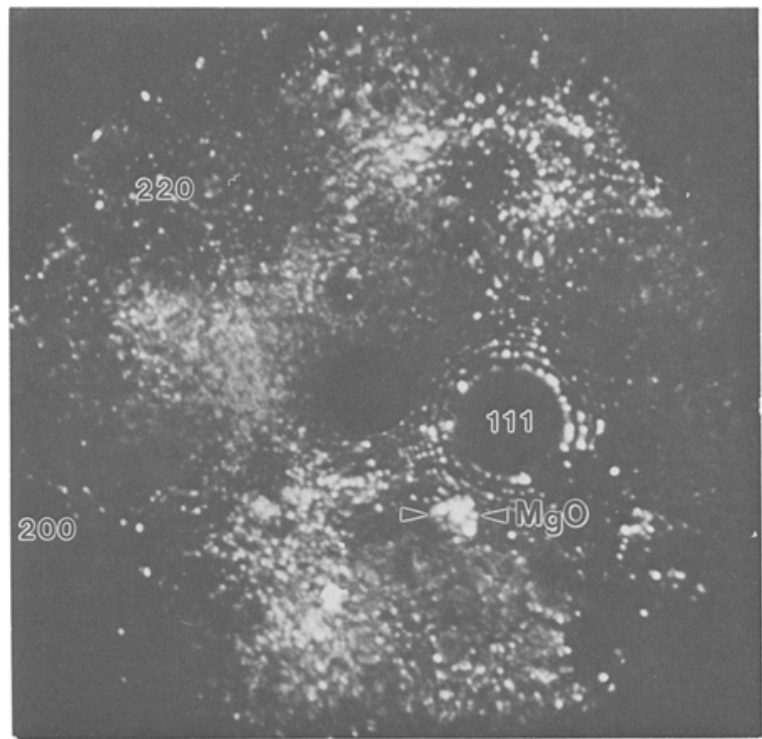

Fig. 12. A field-ion microscope image of an $\mathrm{MgO}$ precipitate in a $\mathrm{Cu}$ matrix. The plane of the $\mathrm{MgO}$ precipitate is parallel to the (111) planes of the $\mathrm{Cu}$ matrix. The diameter of the $\mathrm{MgO}$ precipitate in this figure is approximately 7.3 $\mathrm{nm}$. The $\mathrm{Ne}$ gas is at $8 \cdot 10^{-4} \mathrm{~Pa}$ gauge pressure, and the tip temperature is $40 \mathrm{~K}$.

precipitate exhibits well-developed contrast features outlining its atomic scale geometry.

Figure 14 is a histogram of the number of events versus the mass-to-charge state ratio of a $\mathrm{Cu}$ specimen containing an $\mathrm{MgO}$ precipitate; the ordinate is a logarithmic scale, while the abscissa is a linear scale. This mass spectrum is dominated by the $\mathrm{Cu}$ peaks due to the presence of both singly $\left(\mathrm{Cu}^{1+}\right)$ and doubly $\left(\mathrm{Cu}^{2+}\right)$ charged $\mathrm{Cu}$ ions; the two peaks for each charge state are due to the two naturally occurring isotopes of $\mathrm{Cu}$ with the masses 63 and $65 \mathrm{amu}$. Also note the presence of singly and doubly charged $O$ ions - those peaks are due to the isotope with the mass 16 amu-as well as singly charged $\mathrm{Mg}$ ions from an $\mathrm{MgO}$ precipitate. The presence of a peak due to singly charged hydrogen ions is also present; this peak is from the ambient pressure in the atom probe. This atom-probe analysis was performed at a background pressure of $1.2 \cdot 10^{-8} \mathrm{~Pa}$ and a constant tip temperature of $35 \mathrm{~K}$.

For the analysis of a specimen containing $\mathrm{MgO}$ precipitates, the pulse fraction $(f)$ - the ratio of 

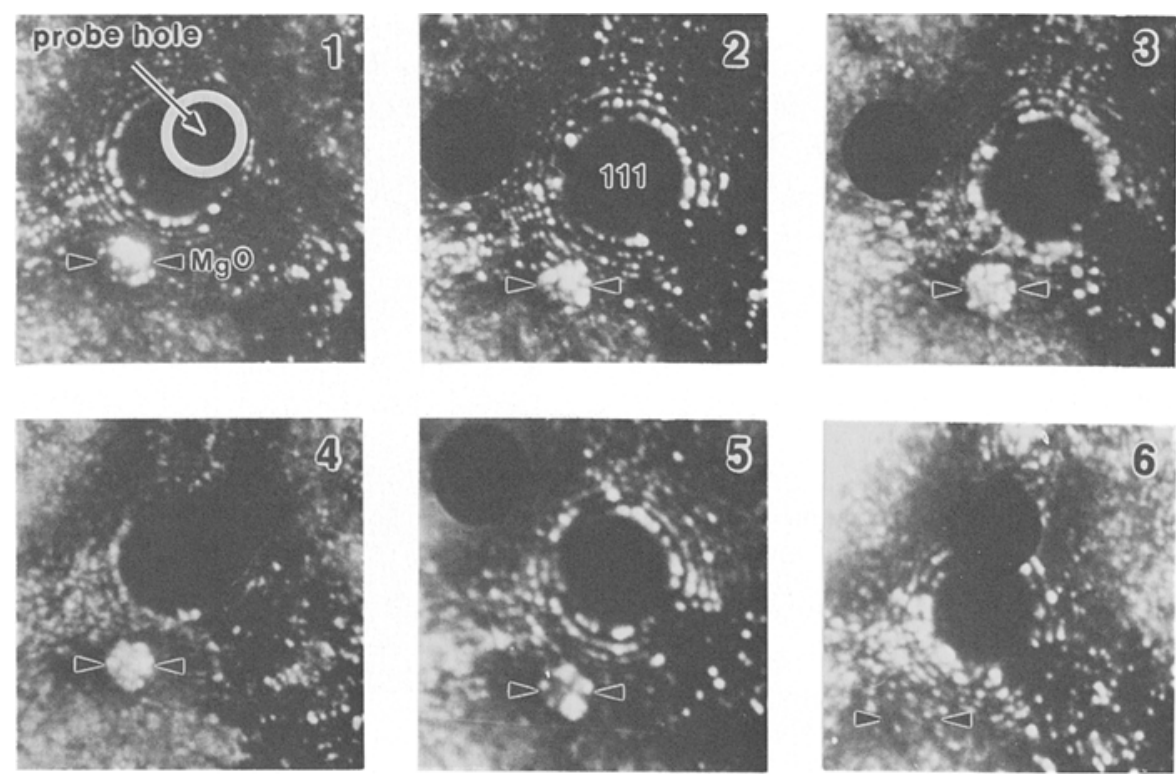

Fig. 13. A series of FIM images showing the pulse dissection of a specimen containing a $7.3 \mathrm{~nm}$ diameter $\mathrm{MgO}$ precipitate in a $\mathrm{Cu}$ matrix; the (222) plane of the $\mathrm{MgO}$ precipitate is parallel to the (111) planes of the $\mathrm{Cu}$ matrix. Individual atoms within a (222) plane of the $\mathrm{MgO}$ precipitate are resolved during the course of this pulsed dissection process. These six micrographs were recorded at various stages of the pulsed dissection process, and the actual dissection is on an atom-by-atom basis. The $\mathrm{Ne}$ gas is at $8 \cdot 10^{-4} \mathrm{~Pa}$ gauge pressure, and the tip temperature is $40 \mathrm{~K}$.

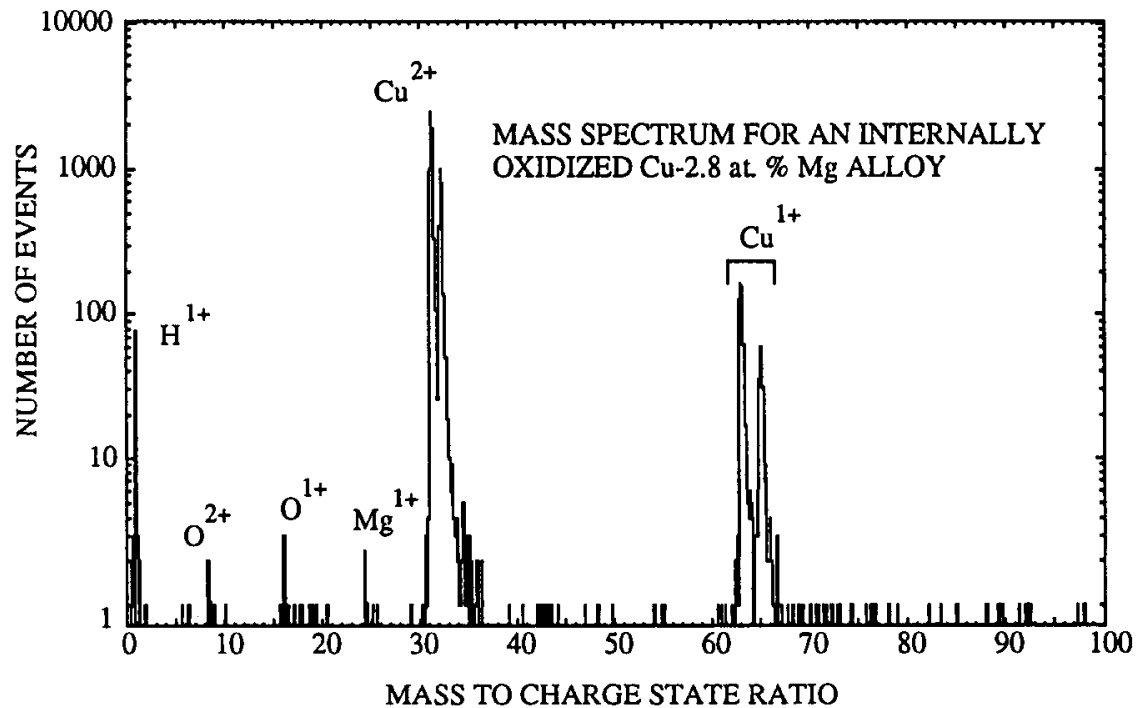

Fig. 14. An atom-probe field-ion microscope mass spectrum of an internally oxidized $\mathrm{Cu} / \mathrm{MgO}$ specimen. The ordinate is the number of events plotted on a logarithmic scale, while the abscissa is the mass-to-charge state ratio of the pulsed field-evaporated ions. This spectrum was recorded at a background pressure of $1.2 \cdot 10^{-8} \mathrm{~Pa}$ employing a pulse fraction $(f)$ of $0.1 ; f$ is the ratio of the pulsed field-evaporation voltage $\left(V_{p}\right)$ to the steady-state voltage $\left(V_{d c}\right)$ on a field-ion microscope specimen. The hydrogen ion signal is from the background pressure in the atom probe. 
$V_{p}$ to $V_{d c}$-is maintained at 0.1 , and a pulse frequency of $15 \mathrm{~Hz}$ is used to dissect the specimen on an atomic scale [39, 46, 47]. The detection efficiency - that is, the ratio of the ions detected to the number of field-evaporation pulses - is maintained at a constant value of 0.0062 , via software in our fully computer-controlled (Macintosh II fx) APFIM [39]; the value of $V_{d c}$ is automatically increased by $10 V_{d c}$ for every 1,000 field-evaporation pulses if no event is detected. This highly controlled procedure results in the continuous and smooth dissection $[39,46,47]$ of a series of (111) planes, as well as other planes on the surface of the approximately hemispherical FIM tip. The central (111) plane exhibited in figure 12 is placed under the probe hole, and the ions collected therefore correspond to a "boring" along a [111] direction. For this geometry the APFIM spatial resolution of a composition profile across a $\mathrm{Cu} / \mathrm{MgO}(111)$ interface is determined by the interplanar spacing of the (222) planes of an $\mathrm{MgO}$ precipitate. The probe hole in the channel electron multiplier array used to view a specimen was placed at a distance from the tip such that its projected diameter covered a small number of atoms [47-50].

Figure 15 is an integral profile of the cumulative number of $\mathrm{Mg}$ or $\mathrm{O}$ ions versus the cumulative number of $\mathrm{Cu}$ plus $\mathrm{Mg}$ plus $\mathrm{O}$ ions [51]. It was created by performing a random area analysis along the [111] direction of the $\mathrm{Cu}$ matrix. The $\mathrm{Cu}$ signal on the ordinate is omitted for clarity because of the large difference between its value and the $\mathrm{Mg}$ or $\mathrm{O}$ values. The projected diameter of the probe hole on the tip is smaller than the diameter of the $\mathrm{MgO}$ precipitate uncovered; this implies that no correction to the data is required [46]. It is seen from this integral profile that the matrix is essentially pure $\mathrm{Cu}$ up to the $\mathrm{Cu} / \mathrm{MgO}$ (111) interface; prior to the $\mathrm{Cu} / \mathrm{MgO}$ (111) interface, only 13 oxygen events were detected out of a total of $10,899 \mathrm{Cu}$ plus $\mathrm{O}$ plus $\mathrm{Mg}$ events for a bulk concentration of $\approx 10^{-3}$ at. fr. oxygen; in addition, only one $\mathrm{Mg}$ event was detected for a bulk concentration of $\approx 9 \cdot 10^{-5}$ at. fr. magnesium. Note carefully that the outermost (222) plane of ions of the $\mathrm{MgO}$ precipitate consists solely of oxygen ions, and the second (222) plane consists solely of magnesium ions. (At this point the specimen failed catastrophically, presumably because the evaporation field of a magnesium ion is considerably lower than that of an oxygen ion.) The APFIM depth resolution of this integral profile is equal to the interplanar spacing along the [111] direction in the $\mathrm{MgO}$ precipitate $-d_{222}=a_{\mathrm{MgO}} /(2 \sqrt{ } 3)=0.121$ $\mathrm{nm}$. The crystal structure of $\mathrm{MgO}$ is $\mathrm{NaCl}-$ type (rock-salt structure), and, therefore, the compositions of point-defect free (222) planes alternate from 100 at.\% oxygen to 100 at.\% magnesium as one travels along a [111] direction from the $\mathrm{Cu}$ matrix to a common [111] direction in the $\mathrm{MgO}$ precipitate (see figures 9 and 11). Thus, the experimental results for this precipitate demonstrate directly-that is, without data deconvolution - that the bonding across a $\mathrm{Cu} / \mathrm{MgO}$ (111) interface has the sequence $\mathrm{Cu}|\mathrm{O}| \mathrm{Mg} \mid \ldots$ and not $\mathrm{Cu}|\mathrm{Mg}| \mathrm{O} \mid$.

Figure 16 is an integral profile along a [111] direction across a $\mathrm{Cu} / \mathrm{MgO}$ (111) interface in another octahedral-shaped $\mathrm{MgO}$ precipitate. In this case, no $\mathrm{Mg}$ events were detected in the matrix, while 7 oxygen events were detected out of a total of 815 events, and this implies a bulk concentration of $<10^{-3}$ at. fr. magnesium and $8.6 \cdot 10^{-3}$ oxygen. Once again, there is an abrupt transition from an essentially pure $\mathrm{Cu}$ matrix to a (222) plane in the precipitate that is 100 at. $\%$ oxygen, and the second (222) plane is 100 at.\% magnesium (again the tip failed catastrophically). The depth resolution is $0.121 \mathrm{~nm}$ for this profile, just as it is in figure 15. Thus, once again, the experimental results for this precipitate demonstrate directly that the bonding across a $\mathrm{Cu} / \mathrm{MgO}$ (111) interface has the sequence $\mathrm{Cu}|\mathrm{O}| \mathrm{Mg} \mid \ldots$ and not $\mathrm{Cu}|\mathrm{Mg}| \mathrm{O} \mid \ldots$.

\section{Conclusions and Discussion}

1. Three different $\mathrm{Cu}(\mathrm{Mg})$ alloys $-0.16,0.7$ and 2.8 at. $\% \mathrm{Mg}$-were internally oxidized to find an alloy composition, annealing temperature and time that yields a high number density $\left(5 \cdot 10^{21} \mathrm{~m}^{-3}\right)$ of small $(<20-\mathrm{nm}$ diameter) $\mathrm{MgO}$ precipitates.

2. A transmission electron microscope study of internally oxidized field-ion microscope specimens of those alloys demonstrated that the num- 


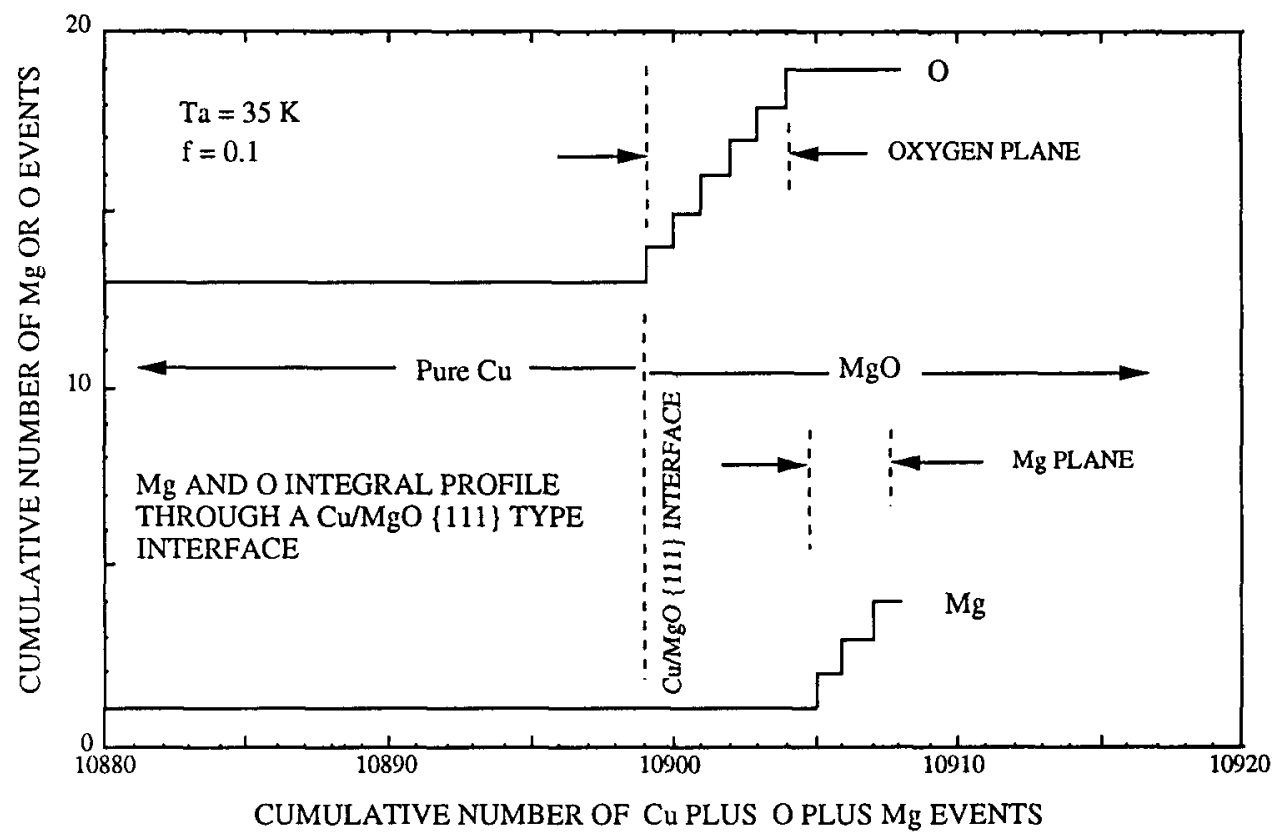

Fig. 15. Integral profiles across a $\mathrm{Cu} / \mathrm{MgO}$ (111) interface detected during a random area analysis along a [111] direction. The cumulative number of $\mathrm{Mg}$ or $\mathrm{O}$ ions detected is plotted versus the cumulative number of $\mathrm{Cu}$ plus $\mathrm{Mg}$ plus $\mathrm{O}$ ions detected. The data were collected for a specimen temperature of $35 \mathrm{~K}$, a pulse fraction of 0.1 , a pulse frequency of $15 \mathrm{~Hz}$, and a background pressure of $1.2 \cdot 10^{-8} \mathrm{~Pa}$. The $\mathrm{Cu}$ signal-not exhibited-disappears at the $\mathrm{Cu} / \mathrm{MgO}(111)$ interface, and the signal is 100 at.\% oxygen until that (222) plane has been completely removed by the field-evaporation process; the next (222) plane is found to be 100 at.\% magnesium. This result indicates directly that the sequence of (111)-type planes across this heterophase interface is $\mathrm{Cu}|\mathrm{O}| \mathrm{MgO} \mid \ldots$. The depth resolution for this chemical composition profile is $a_{0} /(2 \sqrt{ } 3)$, where $a_{0}$ is the lattice parameter of $\mathrm{MgO}(0.420 \mathrm{~nm})$, and is equal to $0.121 \mathrm{~nm}$. The data displayed in this integral profile have not undergone any deconvolution process.

ber density and diameters achieved for the 2.8 at.\% $\mathrm{Mg}$ alloy are suitable for performing atomprobe field-ion microscope studies to determine the $\mathrm{Cu} / \mathrm{MgO}$ interfacial chemistry on an atomic scale. The optimum internal oxidation conditions for our experiments are a time of $1,800 \mathrm{~s}$ at $1,173 \mathrm{~K}$ for the $\mathrm{Cu}-2.8$ at.\% $\mathrm{Mg}$ alloy.

3. A high resolution transmission electron microscope study of $\mathrm{MgO}$ precipitates in a $\mathrm{Cu}$ matrix along the [100] or [110] axial directions demonstrates that the precipitates have the morphology of an octahedron with the facets corresponding to $\{111\}$ planes. The orientation relationship between an $\mathrm{MgO}$ precipitate and the $\mathrm{Cu}$ matrix is cube-on-cube; that is, $\{111\}_{\mathrm{Cu}} / /$ $\{222\}_{\mathrm{MgO}}$ and $\left.\langle 110\rangle_{\mathrm{Cu}} / /<110\right\rangle_{\mathrm{MgO}}$.

4. The $\mathrm{MgO}$ precipitates are semicoherent with the $\mathrm{Cu}$ matrix, even though the lattice misfit parameter $(\eta)$ is $0.1483 ; \eta$ is given by $2\left[\left(a_{\mathrm{MgO}}-a_{\mathrm{Cu}}\right) /\left(a_{\mathrm{MgO}}+a_{\mathrm{Cu}}\right)\right]$ where the $a$ 's are the lattice parameters of the two phases. Misfit dislocations are detected at the $\mathrm{Cu} / \mathrm{MgO}\{111\}$ type heterophase interface, with an average spacing of $1.32 \mathrm{~nm}$. The calculated spacing between the misfit dislocations is $1.38 \mathrm{~nm}$, and since the observed spacing is $1.32 \mathrm{~nm}$, this implies that the fractional difference in these spacings is small. This suggests that the misfit between the $\mathrm{MgO}$ precipitate and the $\mathrm{Cu}$ matrix is accommodated mainly by dislocations.

5. The $\mathrm{MgO}$ precipitates are readily detectable by field-ion microscopy. A recrystallization texture of the $\mathrm{Cu}$ wires is fortuitously [111], hence the $\mathrm{MgO}$ precipitates sit in a $\mathrm{Cu}$ matrix such that a $\{111\}$-type facet of the octahedral-shaped precipitates is perpendicular to the [111] fiber axis of the wires. This implies that a random area analysis of the precipitates along a [111] direction, via the pulsed field-evaporation technique, results in the uncovering of $\mathrm{Cu} / \mathrm{MgO}\{111\}$-type heterophase interfaces.

6. The $\mathrm{Cu}$ matrix is found, via atom-probe 


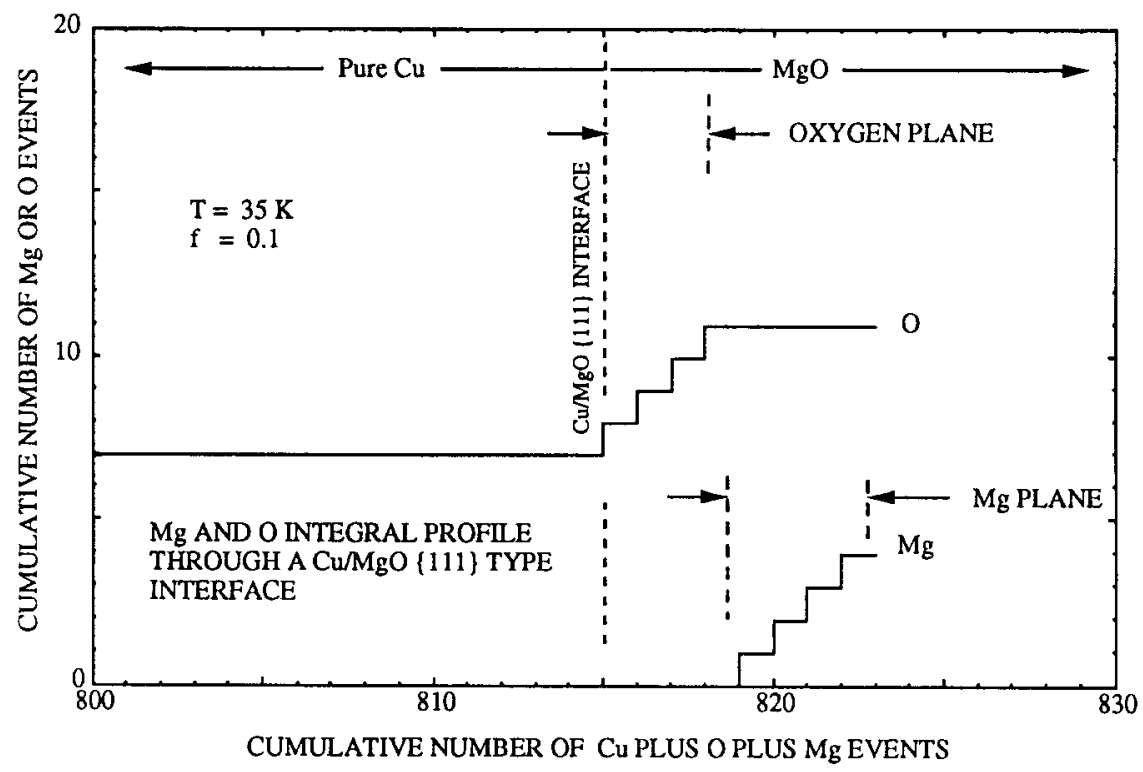

Fig. 16. Another integral profile across a $\mathrm{Cu} / \mathrm{MgO}$ (111) interface detected during a random area analysis along a [111] direction. The cumulative number of $\mathrm{Mg}$ or $\mathrm{O}$ ions detected is plotted versus the cumulative number of $\mathrm{Cu}$ plus $\mathrm{Mg}$ plus $\mathrm{O}$ ions detected. The data were collected for a specimen temperature of $35 \mathrm{~K}$, a pulse fraction of 0.1 , a pulse frequency of 15 $\mathrm{Hz}$, and a background pressure of $1.2 \cdot 10^{-8} \mathrm{~Pa}$. The $\mathrm{Cu}$ signal-not exhibited-disappears at the $\mathrm{Cu} / \mathrm{MgO}$ interface, and the signal is $100 \%$ oxygen until that plane has been completely removed by the field-evaporation process; the next (222) plane is $100 \%$ magnesium. This result indicates directly that the sequence of planes across this heterophase interface is $\mathrm{Cu}|\mathrm{O}| \mathrm{Mg} \ldots$.

field-ion microscopy, to be almost 100 at.\% $\mathrm{Cu}$, with only trace amounts of oxygen $\left(<10^{-3}\right.$ at. fr.) and magnesium ( $<10^{-4}$ at. fr.) after an internal oxidation treatment. No evidence was found for impurity atoms at the $\mathrm{Cu} / \mathrm{MgO}\{111\}$ heterophase interface. This implies that impurity atoms are unnecessary to stabilize the $\mathrm{Cu} / \mathrm{MgO}$ $\{111\}$-type interface.

7. Atom-probe field-ion microscopy analyses reveal that the sequence of atoms across a $\mathrm{Cu} / \mathrm{MgO}\{111\}$ interface is $\mathrm{Cu}|\mathrm{O}| \mathrm{Mg} \mid \ldots$ and not $\mathrm{Cu}|\mathrm{Mg}| \mathrm{O} \mid \ldots$... Thus, the terminating $\{222\}$ type plane for a $\mathrm{MgO}$ precipitate in a $\mathrm{Cu}$ matrix is oxygen, and not magnesium. This result is achieved without any deconvolution of the experimental data. The resolution of the composition profile perpendicular to the interface is equal to the interplanar spacing of the $\{222\}_{\mathrm{MgO}}$-type planes, and this value is $0.121 \mathrm{~nm}$.

\section{Acknowledgments}

This research is supported by the U.S. Depart- ment of Energy Office of Basic Energy Sciences grant No. DEFG02-89ER45403. It also utilized central facilities of the National Science Foundation funded Materials Research Center at Northwestern University. We wish to thank Drs. X.W. Lin and W.A. Chiou for help with specimen preparation and high-resolution electron microscopy, respectively, and Mr. David Chan for useful discussions. Dr. K.L. Merkle was supported by the U.S. Department of Energy, BES-Materials Science under contract \#W31-109-ENG-38.

\section{Notes}

1. That is, $\{111\}_{\mathrm{Cu}} / /\{222\}_{\mathrm{MgO}}$ and $\left.\langle 110\rangle_{\mathrm{Cu}} / /<110\right\rangle_{\mathrm{MgO}}$.

2. This was calculated for the smallest angle $\left(30^{\circ}\right)$ between a $<110>$-type direction and a $<112>$ type direction.

3. The diameter of a precipitate is calculated by first determining the local radius $(R)$ in the region of the 111 pole, and then calculating a liner distance $(\lambda)$ on the surface using the Pythagoras formula. The expression for $\lambda$ is $\left(2 n d_{111} R\right)^{1 / 2}$, where $n$ is the number of 111 planes between the 111 pole and a neighboring pole used to determine $R$, and $d_{111}$ is the interplanar spacing of $\{111\}$ 
Jang, Seidman, and Merkle

copper matrix planes. The value of $\lambda$ provides a length scale for measuring a precipitate's diameter.

\section{References}

1. Metal-Ceramic Interfaces: Proceedings of an International Workshop, edited by M. Rühle, A.G. Evans, M.F. Ashby and J.P. Hirth (Pergamon, Oxford, 1990).

2. Proceedings of the International Symposium of Metal/Ceramic Interfaces, edited by $\mathbf{W}$. Mader and $M$. Rühie, Acta Metall. Mater. 40, supplement (1992).

3. Proceedings of the International Congress: Intergranular and Interphase Boundories in Materials, Colloq. Phys. (Paris) 51, Colloque C1, Supplément au No. 1 (1990).

4. Proceedings of the International Conference on the Structure and Properties of Internal Interfaces, J. Phys. (Paris) 46, Colloque C1, Supplément au No. 4 (1985).

5. Proceedings of the Interface Science and Engineering '87 Conference, J. Phys. (Paris) 49, Colloque C5 Supplément au No. 10 (1988).

6. Proceedings of the International Congress: Intergranular and Interphase Boundaries in Materials, Thessaloniki, Greece, Materials Science Forum, 126-128 (1993).

7. G. Petzow, T. Suga, G. Elssner and M. Turwitt, in Sintered Metal-Ceramic Composites, edited by G.S. Upadhyaya (Elsevier, Amsterdam, 1984), p. 3.

8. H. Gleiter, Nanostructured Mater. 1, 1 (1992).

9. Electronic Packaging in Materials Science, edited by E.A. Geiss, K.N. Tu, and D.R. Uhlmann, Mat. Res. Soc. Symp Proc. 209 (1985)

10. H. Schmalzried, Ber. Bunsenges. Phys. Chem 87, 551 (1983); (a) G.L. Kellogg, Surf. Science 171, 359 (1986).

11. J.L. Meijering and M.J. Druyvesteyn, Philips Research Reports 2, 81 (1947).

12. A.J. Freeman and Chun Li, in Metal-Ceramic Interfaces: Proceedings of an International Workshop, edited by $\mathbf{M}$. Rühle, A.G. Evans, M.F. Ashby and J.P. Hirth (Pergamon, Oxford, 1990), pp. 2-8; (a) Chun Li and A.J. Freeman, Phys. Rev. B 43, 780 (1991).

13. P. Blöchl, G.P. Das, H.F. Fischmeister and U. Schönberger, in Metal-Ceramic Interfaces: Proceedings of an International Workshop, edited by M. Rühle, A.G. Evans, M.F. Ashby and J.P. Hirth (Pergamon, Oxford, 1990), pp. 9-14; (a) U. Schönberger, O.K. Andersen and M. Methfessel, Acta Metall. Mater. 40, S1 (1992).

14. M.W. Finnis, A.M. Stoneham and P.W. Tasker, in MetalCeramic Interfaces: Proceedings of an International Workshop, edited by M. Rühle, A.G. Evans, M.F. Ashby and J.P. Hirth (Pergamon, Oxford, 1990), pp. 35-44.

15. R. Gronsky, Ultramicroscopy 24, 155 (1988).

16. M. Rühle, K. Burger and W. Mader, Microsc. Spectrosc. Electron. 11, 163 (1986); (a) G. Necker and W. Mader, Phil. Mag. Letts, 58, 205 (1988); (b) W. Mader, Z. Metallkde. 80, 139 (1989); (c) W. Mader and B. Maier, Colloq. Phys. (Paris) 51, Colloq. C1, 867 (1990).

17. W. Mader and G. Necker, in Metal-Ceramic Interfaces: Proceedings of an International Workshop, edited by $\mathbf{M}$. Rühle, A.G. Evans, M.F. Ashby and J.P. Hirth (Perga- mon, Oxford, 1990), pp. 222-233.

18. C.S. Smith, Min. and Met. 11, 213 (1930); (a) idem, ibid. 13, 481 (1932); (b) idem, J. Inst. Metals 46, 49 (1931).

19. K.W. Fröhlich, Z. Metallk. 28, 368 (1936).

20. F.N. Rhines, Trans. AIME 137, 246 (1940).

21. F.N. Rhines, W.A. Johnson and W.A. Anderson, Trans, AIME 147, 205 (1942).

22. C. Wagner, Z. Elektrochem. 63, 772 (1959).

23. G. Böhm and M. Kahlweit, Acta Metall. 12, 641 (1964); (a) M. Kahlweit, Prog. Chem. Solid State 2, 134 (1965).

24. R.A. Rapp, Corrosion-Nat. Assoc. Corr. Eng. 21, 382 (1965).

25. J.L. Meijering, in Advances in Materials Research, edited by H. Herman (J. Wiley \& Sons, New York, 1971), vol. 5, pp. 1-81.

26. M. Hansen and K. Anderko, Constitution of Binary Alloys, 2nd ed. (McGraw-Hill, New York, 1958), pp. 594 596; (a) R. Hultgren, P.D. Desai, D.T. Hawkins, M. Gleiser, and K.K. Kelley, Selected Values of the Thermodynamic Properties of Binary Alloys (American Society for Metals, Metals Park, Ohio, 1973), pp. 750-755.

27. J.H. Swisher and E.O. Fuchs, Trans, Metall. Soc. AIME 245, 1789 (1969).

28. B.W. Krakauer, J.G. Hu, S.M. Kuo, R.L. Mallick, A. Seki, D.N. Seidman, J.P. Baker and R.J. Loyd, Rev. Sci. Instrum. 61, 3390 (1990); (a) B.W. Krakauer and D.N. Seidman, Rev. Sci. Instrum 63, 4071 (1992).

29. M.F. Ashby and L.M. Brown, Phil. Mag. 8, 1083 (1963).

30. M. Wilkens in Modern Diffraction and Imaging Techniques in Materials Science, edited by S. Amelinckx, R. Gevers, G. Remaut and J. Van Landuyt (North Holland, Amsterdam, 1970) p. 5.

31. R. Hattenbauer and F. Haider, Scripta Metall. Mater. 25, 1173 (1991).

32. W. Kesternich, Mat. Res. Soc. Symp Proc. 62. 229 (1986).

33. D.J. Pedder, E.D. Boyes, and G.C. Smith, Metal Science J. 12, 437 (1976).

34. K.L. Merkle, Ultramicroscopy 37, 130 (1991); in MetalCeramic Interfaces: Proceedings of an International Workshop, edited by M. Rühle, A.G. Evans, M.F. Ashby and J.P. Hirth (Pergamon, Oxford, 1990), pp. 242-249; K.L. Merkle, M.I. Buckett, and Y. Gao, Acta Metall. Mater. 40, S249 (1992).

35. C. Herring, in Structure and Properties of Solid Surfaces, edited by R. Gomer and C.S. Smith (The University of Chicago Press, Chicago, 1953) Ch. 1; (a) C. Herring, Phys. Rev. 82, 87 (1951).

36. P. Lu and Cosandey, Acta Metall. Mater. 40, S259 (1992).

37. C.S. Barrett and T.B. Massalski, Structure of Metals, 3rd ed. (McGraw-Hill, New York, 1966), pp. 568-569.

38. B.W. Krakauer and D.N. Seidman, Rev. Sci. Instrum. 63, 4071 (1992); (a) D. Chan, D.N. Seidman and K.L. Merkle, unpublished research.

39. (a) T.M. Hall, A. Wagner and D.N. Seidman, J. Phys. E: Sci. Instrum. 10, 884 (1977); (b) J.L. Wiza, Nuc. Instrum. Meth. 162, 587 (1979).

40. D.N. Seidman, J. Phys. F: Metal Phys. 3, 393 (1973); (a) A.S. Berger, D.N. Seidman and R.W. Balluffi, Acta Metall. 21, 123 \& 134 (1973); (b) D.N. Seidman, in Radiation Damage in Metals, edited by N.L. Peterson 
and S.D. Harkness (American Society for Metals, Metals Park, Ohio, 1976), pp. 28-57; (c) D.N. Seidman, Mater, Res. Soc. Symp. Proc. 138, 315 (1989); (d) D.N. Seidman, Mater, Res. Soc. Symp. Proc. 139, 25 (1989).

41. S.S. Brenner, Surf. Sci. 70, 427 (1978); (a) S.S. Brenner and M.K. Miller, J. Metals 35 (3), 54 (1983).

42. R. Wagner, Field-Ion Microscopy (Springer-Verlag, Berlin, 1982), Ch. 4, pp. 80-99.

43. P. Haasen, Metall. Trans. A 16A, 1173 (1985); (a) P. Haasen and R. Wagner, Ann. Rev. Mater. Sci. 15, 43 (1985).

44. T. Sakurai, A Sakai and H.W. Pickering, Atom-Probe Field-Ion Microscopy and Its Applications (Academic Press, New York, 1989), chap. 6, pp. 202-235.

45. D. Blavette and P. Auger, Microsc. Microanal. Mi- crostruct. 1, 481 (1990).

46. R. Herschitz and D.N. Seidman, Acta Metall. 32, 1141 \& 1155 (1984).

47. S.M. Kuo, A. Seki, Y. Oh, and D.N. Seidman, Phys. Rev. Lett. 65, 199 (1990); (a) J.G. Hu and D.N. Seidman, Phys. Rev. Lett. 65, 1615 (1990); (b) D.N. Seidman, Mater. Sci. Eng. A137, 57 (1991).

48. J.G. Hu, Ph.D. thesis, Northwestern University, Evanston, II (1991).

49. J.G. Hu and D.N. Seidman, Scripta Metall. Mater. 27, 693 (1992).

50. B.W. Krakauer, Ph.D. thesis, Northwestern University, Evanston, II (1993).

51. H. Jang, D.N. Seidman and K.L. Merkle, Scripta Metall. Mater. 26, 1493 (1992). 